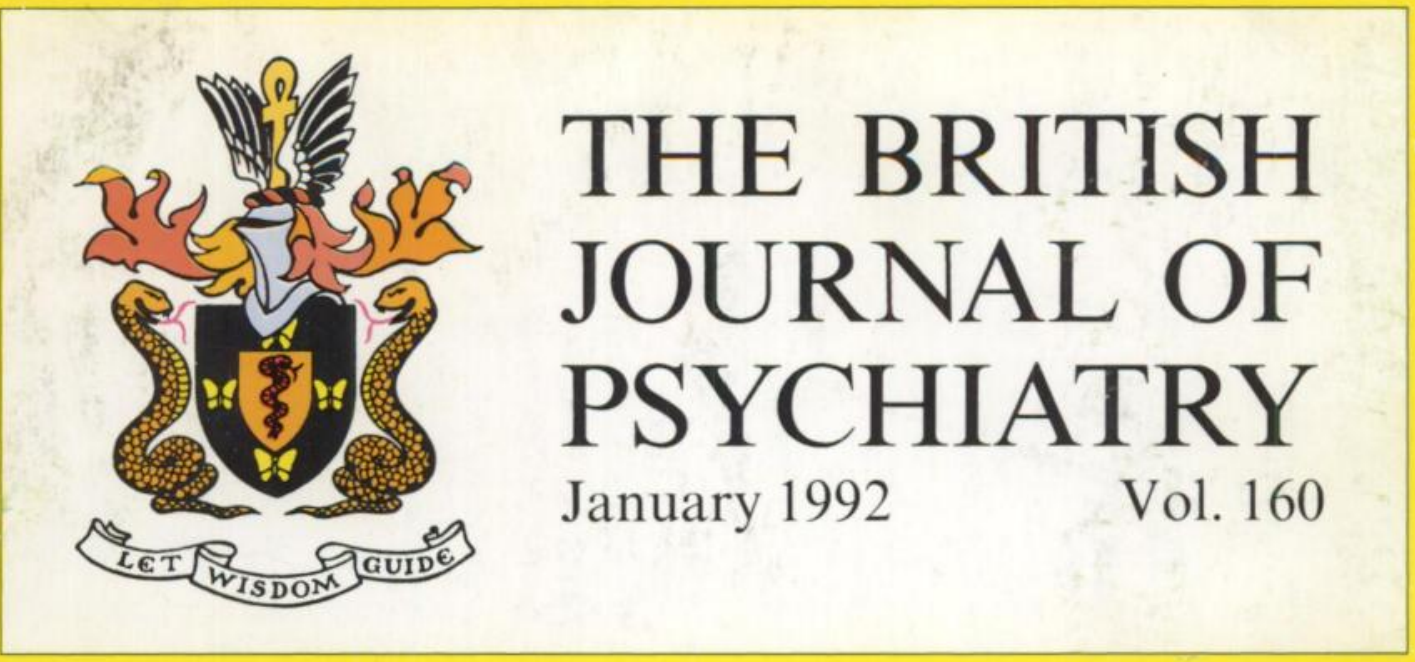

Lecture

Psychological approaches to the management of memory impairments. E. Miller

\section{Annotation}

A critical appraisal of X-linked bipolar illness. Evidence for the assumed mode of inheritance is lacking. J. Hebebrand

\section{Review Articles}

The genetics of personality disorder. $P$. McGuffin and A. Thapar

The fragile-X syndrome. On the way to a behavioural phenotype. J. Turk

\section{Papers}

Tacrine in Alzheimer's disease. Time course of changes in cognitive function and practice effects. S. Eagger, N. Morant, R. Levy and B. Sahakian

Psychodynamics and psychotherapy on an acute psychiatic ward. The story of an experimental unit. M. Jackson and R. Cawley

Spouse-aided therapy with agoraphobics. P. M. G. Emmelkamp, R. van Dyck, M. Bitter. $R$. Heins, E. J. Onstein and B. Eisen

A prospective study of panic and anxiety in agoraphobia with panic disorder. $M$ Basoglu, I. M. Marks and S. Sengun
Risk factors in schizophrenia. Season of birth, gender, and familial risk. A. E. Pulver, $K-Y$.

1 Liang, C. Hendricks Brown, P. Wolyniec, J McGrath, L. Adler, D. Tam, W. T. Carpenter and $B$. Childs

Season of birth of siblings of schizophrenic patients. A. E. Pulver, K.-Y. Liang, P. S. Wolyniec, J. McGrath, B. A. Melton, L. Adler

7 and $B$. Childs

Marital support and recovery from depression. P. N. Goering, W.J. Lancee and $S$. J.J. Freeman

Out-patient compliance with antidepressant

12 medication. E. D. Myers and A. Branthwaite Is hysteria on the wane? A community survey

24 in West Bengal, India. D. N. Nandi, G. Banerjee, S. Nandi and P. Nandi

Emotional distress in the Hebrew Bible.

Somatic or psychological? D. B. Mumford

Point of View

Ethical issues in genetic linkage studies of psychiatric disorders. J. R. Alexander, $B$. Lerer and $M$. Baron

The Current Literature

51 The Worcester development project. R. Turner and $G$. Roberts

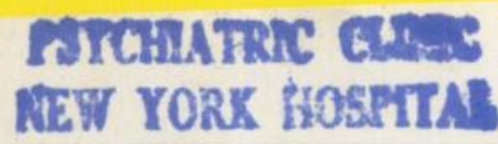

\title{
FEB 031992
}
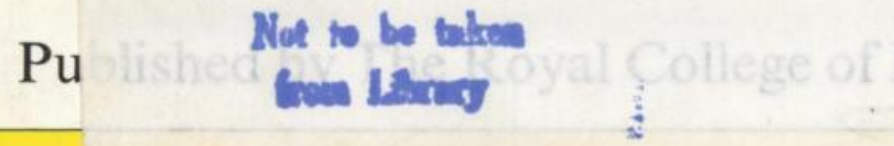

\section{trists}




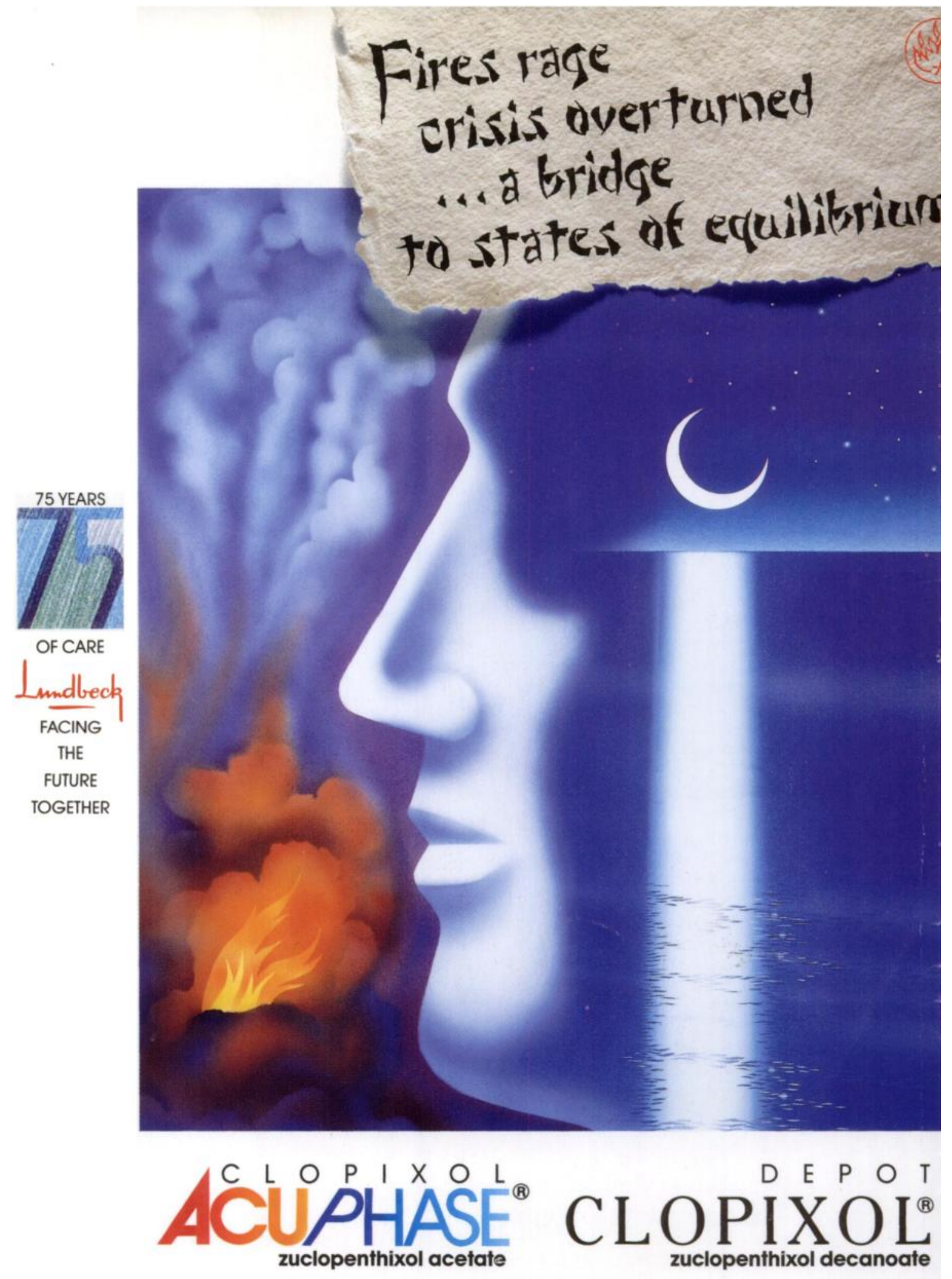

$A$ harmonious way to treat acute and chronic psychosis 


\title{
THE BRITISH JOURNAL OF PSYCHIATRY
}

\author{
VOLUME 160
}

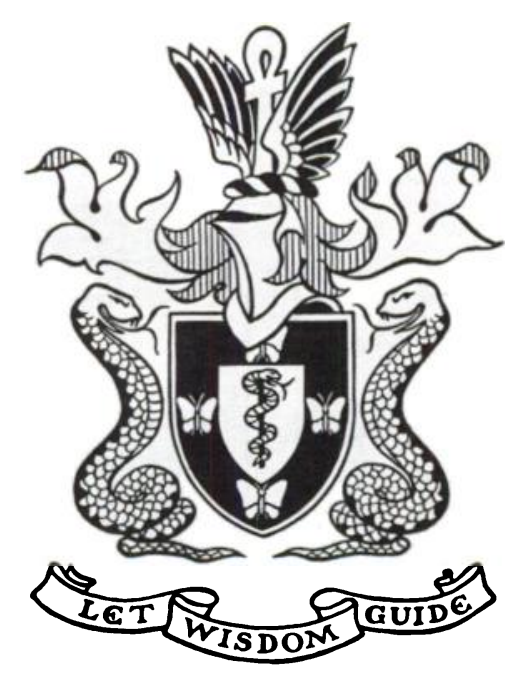

1992

(c) The Royal College of Psychiatrists 


\section{Institute of Psychiatry and Institute of Child Health \\ University of London}

\section{DIPLOMA IN CHILD AND ADOLESCENT PSYCHIATRY An International Course}

A one-year course leading to a Diploma in Child and Adolescent Psychiatry will start in January 1993. The course is designed for psychiatrists, paediatricians and psychologists from overseas and will be particularly suitable for those intending to set up or work in child mental health services in developing countries.

Course content covers assessment, diagnosis and management of children and adolescents with psychiatric disorders, including those with physical illness and chronic handicap; issues relating to planning or implementing services for child mental health with particular reference to the needs of the participants' own countries; research methodology.

Further details available from: Dr A. D. Nikapota, Course Organiser and Tutor, Department of Child and Adolescent Psychiatry, Institute of Psychiatry, 16 De Crespigny Park, Denmark Hill, London SE5 8AF

Applications should be returned by 1 June 1992.

National School of Hypnosis \&. Advanced Psychotherapy

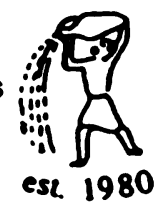

(est 1980 and a founder member of UK Standing Conference for Psychotherapy)

Full Diploma or intensive 6 weekend skillsenhancement courses.

April-June or Oct-Dec.

Ericksonian Hypnosis/ Neuro-linguistic Programming/ Subliminal \& Super Learning/ Personal Growth

Large s.a.e. 36p stamp:

Registrar, N-SHAP, 28 Finsbury Park Road, London N4 2JX.

Tel: 071-359 6991 (24 hours).
INSTITUTE OF PSYCHIATRY

(University of London)

The Maudlsey Hospital and Bethlem Royal Hospital Treatment and Care in Old Age Psychiatry 8th, 9th and 10th July 1992

Topics to include:

Treatment Strategies in Dementia; Age-associated Memory Impairment; Newer Antidepressants in the Elderly; Ethical and Legal Issues; Measuring Change in Depression and Dementia; Non-cognitive Symptoms in Dementia

Speakers will include:

Professor Brice Pitt, Professor Hindmarch, Professor Wilcock, Professor Brenda Costall, Dr Alistair Burns, Dr Rosenvinge, Professor Katona, Professor Anderton, Professor Levy, Dr David Jeffreys, Dr Twining.

Course Fee: $£ 150$ (including buffet lunch and refreshments)

For further information please contact: Mrs Lee Wilding, Conference Ofiice, Institute of Psychiatry, De Crespigny Park, London SE5 8AF.

Telephone: 071703 5411, Ext 3170. Fax: 0717035896 